\title{
Study on the Present Situation and Countermeasures of Agricultural Products Logistics Development in Heilongjiang Province
}

\author{
Shuang Liu \\ College of Ecnomics \& Management, Tianjin University of Science \& Technology, TianJin, 300222, \\ China \\ liushuang994926@163.com
}

Keywords: Agricultural products, logistics, SWOT analysis.

\begin{abstract}
Since ancient times, China is a large agricultural country. Agricultural products are the most basic material need of the people. How to ensure the quality and quantity of agricultural products in circulation has become a subject. Logistics has become the "third profit source", we should combine agricultural products with logistics efficiently to maximize the benefits. Heilongjiang Province is a more fertile region of agricultural products in China. Therefore, this paper through SWOT analysis of agricultural products in Heilongjiang Province to find strengths, shortcomings, opportunities and threats. The author expounded the problems of agricultural products logistics in Heilongjiang Province, and put forward the solution, hoping to promote the better development of agricultural products logistics.
\end{abstract}

\section{Introduction}

China's accession to the World Trade Organization has a far-reaching impact on China's agriculture, whether it is from the agricultural exports or from the expansion of agricultural market share. China's agricultural products have been a lot of benefits. Agricultural products must be the people's daily life consumables. But the crops are easy to rot, relatively bulky, the quality difference between the larger characteristics, so that agricultural products in the transport process loss, which will indirectly lead to price increases. As the price rises, consumers will think that there is no value. In this way, the demand for agricultural products will be reduced, the market has a certain impact; But if the farmers bear this part of price, it will be like "Valley cheap". Farmers make ends meet, gradually they will withdraw from the industry. This kind of action also has a big impact on the market. People lack the logistics awareness, the logistics system imperfect, the lack of logistics personnel and the backward transport facilities will hinder the development of agricultural logistics industry. Therefore, this paper studies the agricultural products in Heilongjiang Province, finds out some shortcomings in this new field and puts forward some solutions to promote its sound and rapid maturity.

\section{The Connotation and Characteristics of Agricultural Logistics}

2.1 Definition of Agricultural Products Logistics. Agricultural products logistics is the agricultural output as the object, through the post-harvest processing of agricultural products, packaging, storage, transportation and distribution logistics links, so that agricultural value-added, and ultimately sent to the hands of consumers activities. Therefore, agricultural logistics not only contains the field of producers but also to cover the field of consumers. Agricultural logistics played a role in communication. The ultimate goal of agricultural products logistics is using low cost and the best service to achieve the crop from the production with the aim of maximizing efficiency.

\subsection{Characteristics of Agricultural Products Logistics}

2.2.1 Effective Control of Logistics Losses. Due to the high water content of most agricultural products, there are certain requirements for temperature and humidity conditions, if the transport logistics do not meet the conditions likely to cause rotting of agricultural products.

In addition, in the logistics process, fruit, eggs and other intolerance squeeze, are also easy to be damaged due to lack of protection ${ }^{[1]}$. In the e-commerce environment, through the construction of 
effective logistics lines, we can reduce the number of agricultural products, thereby reducing the loss of part of agricultural products. For example, in the major cities in the country, SF Express can achieve the next day, and they built a large number of insurance warehouses around, this initiative greatly reduces the loss of agricultural products in the logistics ${ }^{[2]}$.

2.2.2 Logistics Costs Decline. Compared with ordinary commodities, agricultural products require special storage conditions and transport conditions, so the cost has been high. But in the e-commerce environment, in addition to bulk transactions, agricultural products in the course of the transaction, you can better develop the retail market, that is directly from the farm or agricultural enterprises through the agricultural products logistics to the final consumer hands. After assembling the same destination product, the agricultural product logistics enterprise can reduce the operation cost of the agricultural product logistics enterprise through the terminal delivery in the destination city by self-delivery, subcontracting or self-mentioned way ${ }^{[3]}$.

\section{Analysis on Agricultural Production Status and Logistics in Heilongjiang Province}

3.1 Agricultural Products in Heilongjiang Province. Across the 14 longitude, three moist areas, the average annual temperature in Heilongjiang Province, mostly close to zero, the temperature is still relatively low, but the annual rainfall is still relatively adequate, the temperature and precipitation are more suitable for crop growth conditions.

Table 1. Land area of Heilongjiang Province

\begin{tabular}{ccc}
\hline & Land area (ha) & The total area(\%) \\
\hline Agricultural land & 39.55 million & 83.5 \\
\hline Construction land & 1.49 million & 3.2 \\
\hline Unused land & 6.29 million & 13.3 \\
\hline
\end{tabular}

From Table 1, we can find that in Heilongjiang Province, the proportion of agricultural land in the province's land area is very large. Compared with the land conditions of other provinces in the country, the land conditions in Heilongjiang Province have obvious advantages. Heilongjiang Province is famous for "black land". As the soil of Heilongjiang Province contains a variety of organic substances, so where is rich in soybeans, corn, wheat, potato and other crops. These high quality soils provide good growth conditions for agricultural products, good crops, and at the same time promote the development of the economy as a whole.

\subsection{Analysis of Logistics Current Situation}

3.2.1 The Status of Logistics Needs. In recent years, Heilongjiang Province's economic growth is stable, and its demand for logistics has gradually increased.Now, we have a comprehensive access to the information age, through the computer, mobile phones, we can buy the goods at home. At the same time, the market share of agricultural products gradually increased in the online supermarket we can also buy them. Such as Shun Feng established Shun Feng Preferred. Shun Feng Preferred to cover the fresh food, drinks, snacks and other food snacks. They pick fruits and vegetables directly in the origin. And Shun Feng Preferred ensure cold chains in full distribution. As a result, the potential for growth is huge.

3.2.2 Current Situation of Logistics Infrastructure. The railway transport is developed in Heilongjiang Province. Its railway lines have more than 20, and are connected with many domestic provinces. And Heilongjiang has links with North Korea and other neighboring countries. Railway transport in the train traffic is very large, and there is a long transport time during transportation, so that the cost of transport on each piece of goods is very low. Therefore, this mode of transport is very suitable for long-distance trade. The province has four civilian airports, transporting goods through civilian airports, the benefits are also very impressive.

3.2.3 Current Status of Logistics Information. In most villages, the government has built information service stations, including computers, printers, scanners, projectors and other advanced equipment, and equipped with the appropriate service personnel. Many of the agricultural cultivation 
of the greenhouse are installed on the Internet of things equipment, so it saves time and effort. People in the control room can observe the growth of crops, through moving a mouse people can get a variety of crop graphs. This equipment can also be used for automatic irrigation of crops. The application of things in the production has been a lot of benefits, while sales, the effect is also very impressive. Demand side only need to pick up the Internet to find their own items, and then complete the payment on it. This eliminates the need for a large number of intermediate links. Agricultural products are cheap, and customers can eat fresh fruits and vegetables. Cooperative staff quarantine of pesticides, the quarantine results will become two-dimensional code. Customers only need to use mobile phones to scan two-dimensional code, you can learn the situation of pesticides, customers eat assured.

3.2.4 Market System Current Situation. The province has always around the government to develop policies and actively promote the construction of modern market system. Actively strive for national policies to promote the construction of large and medium-sized commodity wholesale farmers market; Construction and re-preparation of the network so that the professional market is more prominent. In the trade with Russia, the construction of its unique market and constantly improve the Russian trade to improve the level of export trade.

\section{A Brief Introduction to SWOT Analysis}

\subsection{Analysis of Internal Advantages}

4.1.1 The Advantages of Natural Resources. The province has a large area of land. There are two major plains and four major river systems. Rich terrain and abundant water resources make the crop resources in Heilongjiang Province rich and varied, variety of crops, high yield. High quality will enhance the desire of consumers to buy and promote the sale of agricultural products.

4.1.2 Advantages of Integrated Transportation Network. Heilongjiang Province is located in the core position of the Northeast Asian economic circle, and gradually built to Harbin as the center, covering the entire province, linking the country and Russia, South Korea and other countries of the scope of transport. According to the different characteristics of agricultural products, as well as the supply speed, supply costs and other factors, taking into account the need for which one or several types of transport, will be more accurate to meet customer needs.

4.1.3 The Development of Information Technology. The Internet is fully covering the entire province of Heilongjiang. In order to enhance the degree of rural information, the government set up information service stations. Service station has a professional network of technical personnel, but also equipped with computers, printers, scanners and other corresponding equipment. With a professional service station, it is more convenient to publish and receive information, making the information more timely and accurate.

4.1.4 The Establishment of Agricultural Products Logistics Company. The province has a number of related companies to set up, like the East logistics company which is a specialized provider of agricultural products and services company. And Heilongjiang Province is actively building logistics park and related third-party logistics companies and some large enterprises have set up their own distribution center.

\subsection{Disadvantage Analysis}

4.2.1 Infrastructure and Equipment Behind. Some fresh products need to be refrigerated during transport, but there are few vehicles with refrigerated equipment. In the agricultural product storage process, some agricultural products have strict requirements on the temperature. The lack of refrigeration in the warehouse, refrigeration equipment, so it cannot guarantee the freshness of agricultural products. There are some agricultural products on the packaging have some requirements, due to backward packaging equipment, some agricultural products cannot be better packaging, which will reduce the desire of consumers to buy.

4.2.2 Logistics Management Level is Low. The province lacks effective management. Agricultural products logistics still remain in the agricultural products from the output to the consumption of the initial stage, it lacks and e-commerce and other modes of effective connection.In 
the logistics operations, it lacks a unified standard, the operating process is not standardized, which will lead to further increase the cost of logistics.

4.2.3 Lack of Logistics Professionals. Most of the personnel engaged in basic logistics activities are not learning logistics professional, their lack of logistics concept, the ability to control the equipment is not very strong which is the development of the entire logistics industry is a disadvantage. Enterprises in personnel training, low degree of attention and lower input costs which also resulted in the lack of logistics professionals.

\subsection{Opportunity Analysis}

4.3.1 The Government Attaches Great Importance. The state concerned about the people's livelihood attach importance to farmers and increase the province of Heilongjiang and other provinces in the construction of ecological civilization infrastructure. In order to improve the infrastructure of the various regions, the standard of living has been improved. A number of documents have been promulgated and rectification measures have been formulated. With the strong support of the state and government, agricultural logistics industry has a strong backing will be more vigorous development.

4.3.2 Market Prospects. The province's agricultural products exported to Russia and other countries making the agricultural industry market prospects broader. With the continuous improvement of quality of life customers also began to pay attention to the quality of agricultural products and good quality products will win a greater market share.

\subsection{Threat analysis}

4.4.1 Intense Market Competition. Agricultural products logistics is still in its infancy some foreign-funded enterprises and foreign joint ventures are to enter the Chinese market. The United States FedEx, United Parcel company, Danish Maersk and so mature logistics companies also spotted the opportunity for market development have started in our country to set up companies in order to compete for agricultural products market share.

4.4.2 Lack of Sound Market Mechanism. Agricultural logistics is still in the basic stage of the market mechanism is imperfect, production, trade and other logistics activities and other factors are affected. This is the basic problem that needs to be dealt with in the development of the industry.

\section{Problems in the Development of Agricultural Products Logistics in Heilongjiang Province}

5.1 Low Degree of Information Technology. Due to the low degree of information technology, the relevant information can not be accurate and effective delivery. The opacity of the information will undoubtedly lead to higher prices and lower demand for purchases. Some agricultural products should be sold in a fresh state but the information is not timely may cause delayed sales of agricultural products. Even if the use of a number of information technology or stay in the bar code, EDI technology, RFID technology and other single technology did not form a complete logistics information system. So logistics information construction is not perfect.

5.2 Facilities and Equipment Level is Low. In the planting process, there is no introduction of advanced technology and equipment is simply relying on farmers for many years of cultivation experience can not ensure the quality of agricultural products. In the storage link, because there is no storage environment for agricultural products and the establishment of a separate warehouse, it is impossible to ensure the quality of agricultural products. In the transport link, the truck is not equipped with refrigeration, frozen equipment so that some fresh products in transit on the deterioration occurred. Packaging links, the same packaging equipment due to backward can not be some of the products for the correct packaging. Personnel in the handling process of violent handling so that a great degree of damage to agricultural products.

5.3 Low Degree of Standardization. Agricultural products and other products have a set of their own standardized system. How to produce, when it is suitable for picking, crop storage conditions are not the same. How to use advanced equipment handling, how to transport the route optimization and so on these small logistics links to develop a standardized system. Whether it is the same logistics enterprises in different sectors of the operation or the operation of different logistics enterprises 
because of the lack of standardized operating procedures to increase logistics costs hinder the development of agricultural logistics industry in Heilongjiang Province.

5.4 Lack of Talent. The development of agricultural logistics requires two major categories of talent. One is engaged in logistics research work of the researchers and other is a certain experience of logistics and technical personnel. But now, these two aspects of talent are very rare.

\section{Countermeasures and Suggestions}

6.1 Enhance the Information Construction. From the agricultural production stage of scientific information control and keep abreast of the growth of crops. In the transport, the overall scheduling of the various vehicles in the shortest possible time delivery. Through the management of information systems, products can be scheduled through the system to prevent the harvest of agricultural products is not fresh. Due to the accuracy and speed of information, it can improve the efficiency of crop circulation and reduce the probability of intermediate fare increase.

6.2 Enhance the Level of Logistics Facilities and Equipment. The introduction of a large number of cold storage to find the best storage temperature and the appropriate warehouse and a different storage; In the transport, the vehicle is equipped with refrigeration equipment to reduce the deterioration of agricultural products; In the packaging, the purchase of advanced packaging equipment for effective packaging; In the loading and unloading, handling links, the purchase of advanced removal equipment. For example, mechanical arm, forklift, automatic guide car and so on. Through the use of advanced facilities and equipment enhancing the logistics of the various activities. 6.3 Enhance the Degree of Standardization. From the seven basic functions of logistics to start,the establishment of a standardized system. In the conduct of the logistics activities, we must strictly abide by the unified constitution. In the illustrations and identification of standardization so that some of the complex bar code can be identified by the naked eye. Consolidate documents and tickets for logistics to save time on the input and collection of commodity information

6.4 Increase the Training of Talent. One is scientific research personnel to encourage engaged in the logistics industry researchers. The other is an experienced logistics technical staff to cultivate all aspects of the ability and technical professionals to guide the work. Colleges and universities should also expand the enrollment, and more for the country to cultivate a good logistics industry talent. In the school curriculum to increase the practice of the link between the theory and practice will enable students to be more comprehensive development.

\section{Acknowledgement}

I would like to show my deepest gratitude to my supervisor, who has provided me with valuable guidance in every stage of the writing of this thesis. I' d like to thank all my friends, especially my three lovely roommates, for their encouragement and support.

\section{References}

[1] Wang Fahui, Discussion on the Development Trend of E - commerce Teaching from Market Development Mechanism, E - commerce, vol.05, pp. 95-96, 2015.

[2] Li Ruifen, Analysis on the Present Situation and Development Trend of Cross - border E commerce Logistics Distribution, Value Engineering, vol.14, pp.41-42, 2015.

[3] Ma Zengjun, Development of China 's Agricultural Products Wholesale Market 30 Year review and outlook, China circulation economy, vol.05, pp. 5-10, 2015.

[4] Kamal Lamsal, Philip C. Jones, Barrett W. Thomas, Harvest logistics in agricultural systems with multiple, independent producers and no on-farm storage, Original Research Article Computers \& Industrial Engineering, vol. 91, pp. 129-138, 2016. 
[5] Chun Sheng Goh, Birka Wicke, Judith Verstegen, André Faaij, Martin Junginger, Linking carbon stock change from land-use change to consumption of agricultural products: A review with Indonesian palm oil as a case study, Journal of Environmental Management, vol. 184, pp. 340-352, 2016.

[6] Omar Ahumada, J. Rene Villalobos, A. Nicholas Mason, Tactical planning of the production and distribution of fresh agricultural products under uncertainty, Agricultural Systems, vol. 112, pp. 17-16, 2012.

[7] Omar Ahumada, J. Rene Villalobos, Operational model for planning the harvest and distribution of perishable agricultural products, International Journal of Production Economics, vol. 133, pp. 677-687, 2011.

[8] Yandra Rahadian Perdana, Logistics Information System for Supply Chain of Agricultural Commodity, Procedia - Social and Behavioral Sciences, vol. 63, pp. 608-611, 2012.

[9] Hong Lan,Main Characteristics and Development Trend of Agricultural Products Circulation in China, China circulation economy, vol.05, pp. 25-26, 2015.

[10]J. Mehmann, F. Teuteberg, The fourth-party logistics service provider approach to support sustainable development goals in transportation - a case study of the German agricultural bulk logistics sector, Journal of Cleaner Production,vol.126,pp. 328-393, 2016. 